\title{
Satellite data in thermal range for natural and technogenic ecosystems monitoring
}

\author{
Nikita Yakimov ${ }^{1,2 *}$,Evgenii Ponomarev ${ }^{1,3}$, and Tatiana Ponomareva ${ }^{1,3}$ \\ ${ }^{1}$ Siberian Federal University, Krasnoyarsk, 660041, Russian Federation \\ ${ }^{2}$ Federal Research Center «Krasnoyarsk Science Center SB RAS», Krasnoyarsk, Russian Federation \\ ${ }^{3}$ V.N.Sukachev Institute of Forest, Siberian Branch, Russian Academy of Sciences, Krasnoyarsk, 660036, Russian Federation
}

\begin{abstract}
A method for recovery monitoring in post-fire and post-technogenic landscapes was proposed based on satellite data in a wide spectral range, including the infrared band data. A decrease in the spectral surface albedo in post-fire areas, caused by the destruction of on-ground vegetation, provokes excessive heating of the surface and upper soil layer. Surface thermal anomalies were evaluated under conditions of changes in the heat-insulating properties of vegetation and ground cover. The relative temperature anomalies in post-fire plots (overestimation up to $30 \%$ compared to non-disturbed territory) are typical for permafrost conditions of Siberia. Similar process was recorded for both natural (post-fire) and posttechnogenic landscapes. Within 22 years after the fire, thermal insulation properties of the vegetation cover were restored. Thus, the relative temperature anomaly (of $3 \pm 1 \%$ ) has reached the background value. In post-technogenic plots, conditions are more "contrast" compared to the background, and restoration of the thermal regime takes significantly longer (>60 years). "Neo-technogenic ecosystems" with specific soil thermal regimes compared to the background ones are formed both for reclaimed and for non-reclaimed post-technogenic plots. On average, surface temperature has overestimated at least by $10-15 \%$ in posttechnogenic plots compared to non-disturbed territory.
\end{abstract}

\section{Introduction}

Nowadays, long-term forest destruction monitoring in Siberia is impossible without satellite monitoring tools [1, 2]. Thematic processing of multispectral satellite data makes it possible to identify vegetation damage and evaluate seasonal or intraseasonal dynamics of disturbed vegetation and soils. Thus, modern approaches based on remote sensing data make it possible to control and predict the state and successions in natural or technogenic ecosystems. Satellite monitoring allows estimating the annual increase of vegetation disturbances in Siberia, which are associated with a number of destructive natural (insect pests, wildfires, other natural processes) or human-made factors (logging, activities of the mining complex, etc.).

Disturbance of heat-insulating properties of the soil and the vegetation cover is the reason for the change in thermal regime within local areas. When such changes accumulate, they should be considered a significant factor regulating the state and dynamics of ecosystems and soil and permafrost characteristics [3-6]. Up to $20 \%$ of permafrost larch forests in Siberia $[7,8]$ are subject to post-fire changes in vegetation and surface and soil temperature regimes. Anomalous heating of the surface and the soil layer is also observed in post-technogenic plots (open-pit mining, quarries, overburden dumps, loggings, etc.) under the strong mechanical impact on vegetation cover and soil. Landscape thermal regime monitoring and the development of remote sensing techniques in monitoring recovery processes are urgent. The issue can be effectively solved using satellite data in a wide spectrum range, including data in the infrared (IR) range.

The destruction of on-ground cover affects surface albedo, emissivity, moisture, and water regime of the upper soil horizons. As a result, the temperature regime of soils changes significantly compared to the background areas. Such thermal anomalies of surface and soil can remain significant for a long time in post-fire plots [5-7] and posttechnogenic areas when the ground cover and soils are disturbed mechanically $[9,10]$.

The main aim of the study was to compare long-term peculiarities of thermal anomalies in post-fire and posttechnogenic plots in Siberia based on Landsat survey data in the infrared (IR) range. In addition, using time series of Terra/MODIS satellite data, we performed indirect assessments of disturbed ecosystems recovery in terms of disappearing the spectral features anomaly (spectral albedo in the short-wavelength bands and vegetation index) compared to characteristics of non-disturbed background areas.

\footnotetext{
*Corresponding author: nyakimov96@mail.ru
} 


\section{Initial data}

For technogenic ecosystems, we used satellite images of average spatial resolution (15-60 m) from Landsat 2-8 for 1975-2021, which are freely available in The United States Geological Survey (USGS) database (https://earthexplorer.usgs.gov/, accessed on 30 October 2021). The surface temperature was evaluated from the calibrated B6 channel $(\lambda=10.4-12.5 \mu \mathrm{m}$, Landsat-5/TM - Thematic Mapper), B6/1 channel (Landsat-7/ETM Enhanced Thematic Mapper), and B10 channel $(\lambda=10.6-11.9 \mu \mathrm{m}$, Landsat-8/OLI - Operational Land Imager). Using calibration constants from the metadata files, we implemented the radiometric correction method to the initial data [11]. Calibrated data from the NIR $(\lambda=0.63-0.69 \mu \mathrm{m})$ and $\operatorname{RED}(\lambda=1.55-1.75 \mu \mathrm{m})$ channels were used to calculate Normalized Difference Vegetation Index (NDVI).

For natural ecosystems, we used low spatial resolution survey data $(250-1000 \mathrm{~m})$ from Terra/MODIS (Moderate Resolution Imaging Spectroradiometer) for 1996-2018. Standard products L2G and L3 used (free USGS database, https://lpdaac.usgs.gov/dataset_discovery/modis, accessed on 30 October 2021). To analyze NDVI and spectral albedo, we operated with reflectances measured in MODIS bands \#1 $(\lambda 1=0.620-0.670 \mu \mathrm{m})$ and \#2 $(\lambda 2=0.841-0.876 \mu \mathrm{m})$ (standard product MOD09GQ). To analyze surface temperature anomalies, we used the MOD11A1 standard product. We used 10-day averaged data across the entire initial data set, focusing on the disturbed ecosystem's recovery succession stages. A monthly data average procedure and a procedure of spatial averaging within each post-fire or posttechnogenic plot were applied.

The relative NDVI and temperature field anomalies were defined in percentage compared to background ones (percent relative to the average long-term norm).

\section{Methods and data processing}

In the current research, we analyzed data for typical taiga region of Central Siberia $\left(59-66^{\circ} \mathrm{N}, 90-107^{\circ} \mathrm{E}\right)$. Zonal and intrazonal soil types represent the soil cover of the study area. The forest-steppe part of the territory is characterized by full-profile soils with a well-differentiated profile, as well as with high humus content, and a heavy granulometric composition. Moderately thick chernozems primarily represent soils. The soils in the middle taiga zone dominated by podzols. Peat, gley, and humus soils are typical in areas with poor drainage. Parent rocks determine the genetic specificity of the soils in the permafrost zone. The soil depth is low $(0.20-0.50 \mathrm{~m})$ here, and the soil profile's vertical differentiation is weak. The permafrost level $(<1.0 \mathrm{~m})$ depends significantly on the topography [12]. Permafrost is widespread on leveled elements and not be present in the soil profile on drained areas of slopes and valleys. Periodic freezing and thawing of the soils determine the soil structure, the low rate of humus accumulation in the soil, the peculiarities of moisture transport, waterlogging. Moreover, freezing and thawing processes affect slightly acidic or neutral soil reaction and loamy or clayey granulometric composition with a high gravel content in the lower part of the soil profile [13].

Wildfires affect soil properties [12, 17] and change the soil structure [4, 14]. After a wildfire, the soil loses upper horizon, the level of permafrost occurrence decreases, and the soil formula transforms to: Opir-O(F + H)pir-CR-C. Under extreme heat stress, the profile structure can transform more significantly. Depending on the degree of litter burnout, the soil formula changes to: $\mathrm{O}(\mathrm{F}+\mathrm{H})$ pir-CRpir-C or $\mathrm{O}(\mathrm{H})$ pir-CRpir-C. Locally, complete burnout of the upper organic horizons of the soil is possible [14]. As a rule, the upper part of the soil profile has a thin humus-accumulative (underdeveloped) horizon $\mathrm{W}$ or a fragmented coarse humus horizon Oao both in case of post-fire mineralization of cryozems and in case of technogenic transforming of soils. Such soils formula is: Oao(W)-C.

Under the technogenic impact (open-pit mining, quarries, overburden dumps) the soil cover significantly transforms. Under the prevailing conditions of soil formation, specific technogenic surface formations (abralites, lithostrats) and anthropogenically transformed types of natural soils are formed. On the territory of the residential zone, urban soils are formed such as urbiquazizems and artindustrates (Technosols).

The general regularities of soil transformation after destructive effects on heat-insulating (thermo-isolation properties) covers (an increase in thawing depth, an increase in soil moisture due to thawing of schlieren and wedge ice, an increase in gleying, a cryoturbation processes) depend on the vegetation and soil restoration succession. The relative temperature anomalies in post-fire plots $(\mathrm{PF})$ are typical for permafrost conditions of Siberia. Similar process was recorded for both natural (post-fire) and post-technogenic landscapes [4]. Thus, the effect of a post-fire increase in the thawing depth (by $30-100 \%$ in the first year after the fire) [4] leads to a unique path of soil evolution, when the underlying gleyed rock layers are included in soil formation for a significant period [15]. This type of evolution is possible only in the permafrost zone. Figures 1-2 show the technogenic objects studied. 

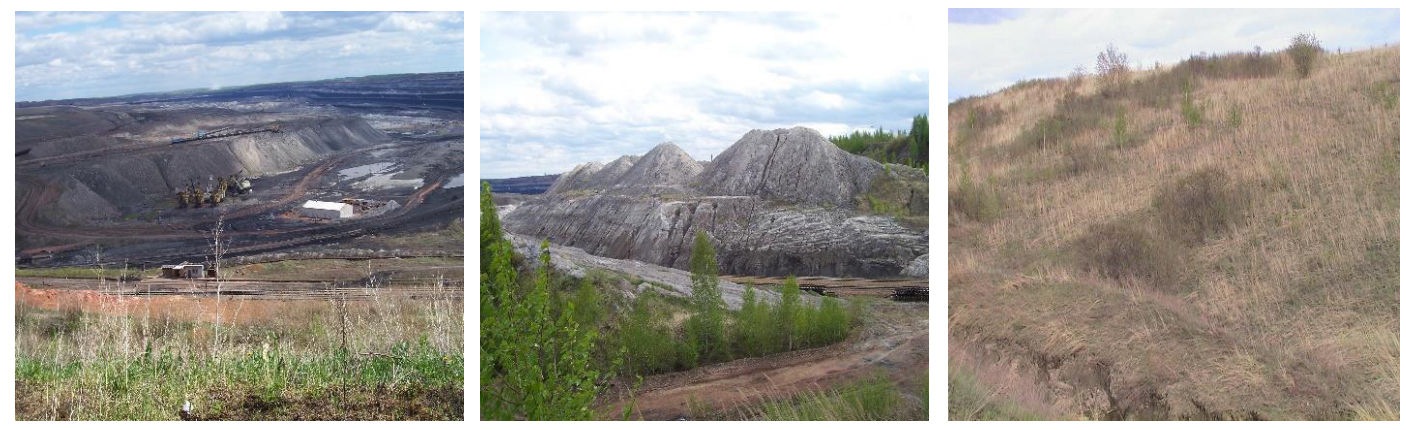

Fig. 1. Borodinsky Coal Mine quarries and overburden dumps (Krasnoyarsk Region, Siberia), 2010-2017.
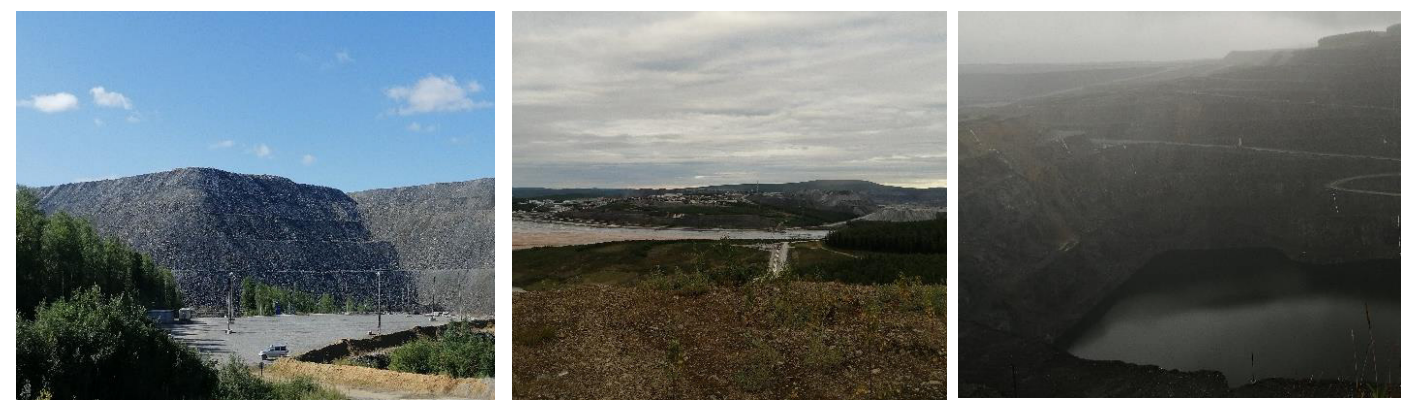

Fig. 2. Olympiada Mining Complex quarries and overburden dumps (Krasnoyarsk Region, Siberia), 2019.

We selected satellite data for the summer growing season (July), making it possible to trace sporadic maxima of heat anomalies. For post-fire plots investigating we analyzed data on 10-15 fires registered annually in Siberia. Next the spectral anomalies dynamics were analyzed for two technogenic sites: the Borodinsky Coal mine (BCM) for 1955-2018 and the Olympiada Mining Complex (OMP) for 1989-2019.

The satellite data time series allowed us to estimate the disturbed land restoration in terms of spectral and thermal anrelative anomalies compared to non-disturbed background areas. We assessed long-term changes in anomalies of spectral characteristics (spectral albedo and surface temperature) and the state of vegetation cover (NDVI) compared to background areas. The period of stabilization of the properties of disturbed ecosystems was evaluated as well. Using ArcMAP GIS software we implemented the procedure of temporal and spatial average of a large amount of data. We estimated the anomalies of albedo, surface temperature, and NDVI during 1, 5, 10-12, 20-22, 40, 55-60 years after destructions in percentage compared to the long-term statistical norm. Figures 3-5 demonstrate different stages of recovering in terms of thermal fields.
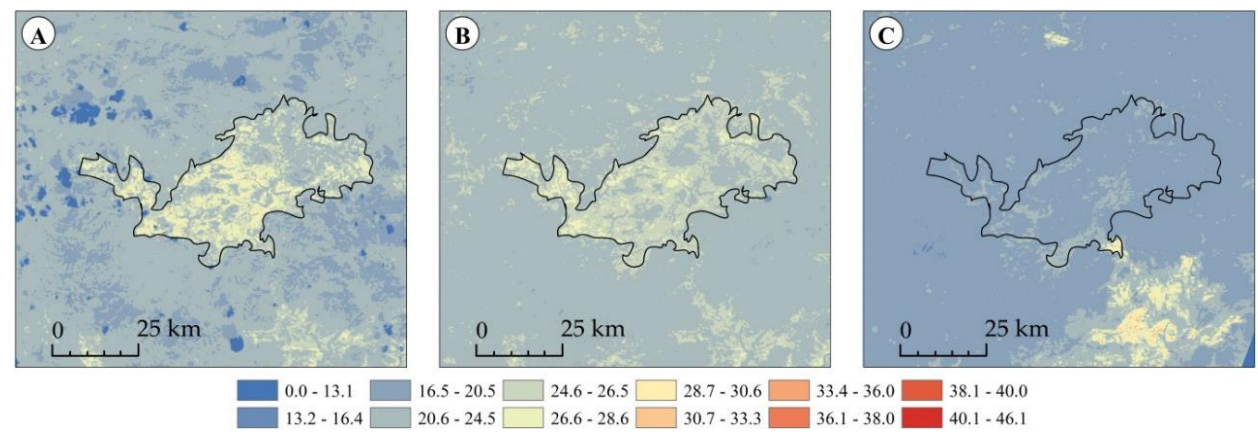

$16.5-20.5 \square 24.6-26.5 \square 28.7-30.6 \square-33.4-36.0 \square-38.1-40.0$ $20.6-24.5 \square 26.6-28.6 \square+30.7-33.3 \square 36.1-38.0 \square+40.1$ - 46.1

Fig. 3. Dynamics of surface temperature in post-fire plot (PF) burned in 1997 after the 1st year of recovery (A), 10-years recovery in 2006 (B), and 20-years recovery in 2016 (C). Data from Landsat imagery in thermal range. 

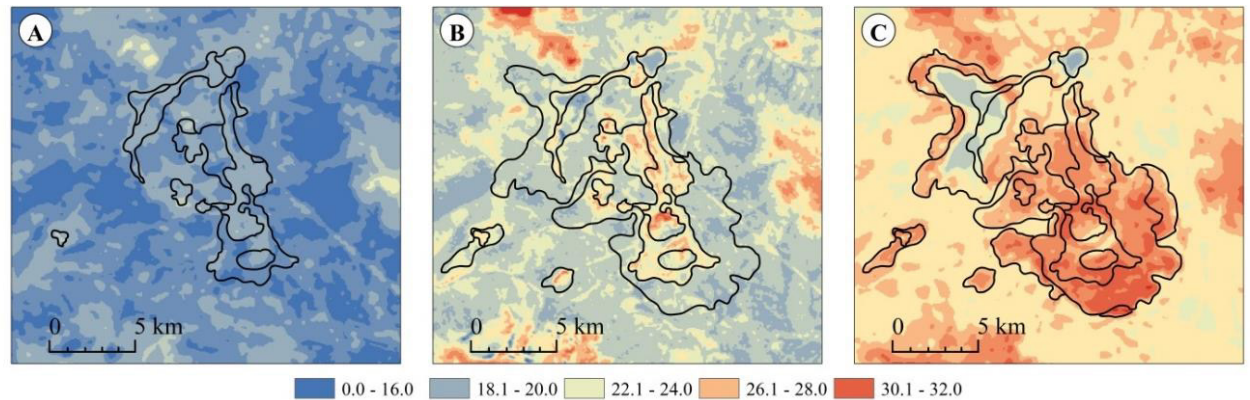

$0.0-16.0$

$18.1-20.0 \square 22.1-24.0 \square 26.1-28.0$

$30.1-32.0$

$32.1-34.0$

Fig. 4. Dynamics of surface temperature in OMP plot with the identification of different-aged zones of a technogenic ecosystem formation (since 1989) on dumps in 1989 (A), 2000 (B), and 2019 (C). Data from Landsat imagery in thermal range.
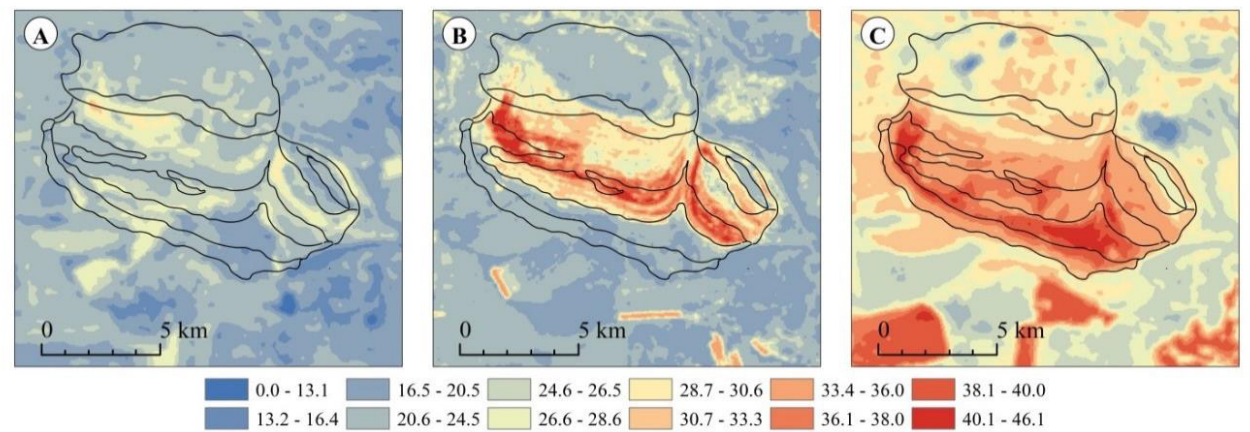

Fig. 5. Dynamics of surface temperature in BCM plot with the identification of different-aged zones of a technogenic ecosystem formation (before 1975) on dumps with reclamation in 1990 (A), 2000 (B), 2018 (C). Data from Landsat imagery in thermal range.

The relative anomalies of the surface temperature we evaluated as ratio of absolute values of disturbed plots overestimation to the temperature of background territory $\left(\Delta \mathrm{T} / \mathrm{T}_{\mathrm{bg}}\right)$ in percent. The same procedure was applied for estimating of spectral albedo anomalies $\left(\Delta \alpha / \alpha_{\mathrm{bg}}\right)$ and NDVI anomalies $\left(\Delta \mathrm{NDVI} / \mathrm{NDVI} \mathrm{bg}_{\mathrm{bg}}\right)$. Based on the data obtained, we constructed the dynamics of temperature anomaly and NDVI index after the impact of different factors.

\section{Results and Discussion}

A decrease in the spectral albedo in post-fire (fire damage) and post-technogenic areas (due to mechanical damage to the surface soil layer [16]) provokes excessive heating of the underlying surface, which persists for decades. This effect occurs in the summer, late spring, and early autumn at positive air temperatures. It was found that after fires, surface temperature changes by an average of up to $33 \%$ compared to the background. The maximum recorded rise was $46 \%$. Surface temperature is rising due to the high degree of suppression of vegetation [17]. For at least 10 years, the level of anomalies decreases to $11 \%$, with a maximum of $20 \%$, while for at least 20 years, the amplitudes of anomalies decrease to the level of background values and measurement errors in the range from 3-5\%. When analyzing the data on temperature of post-technogenic areas, it was revealed that high values of thermal anomalies from 70 to $100 \%$ in the initial period gradually decreases to $19-20 \%$ after at least 40 years of recovery. A greater rate of decline in the temperature anomaly is observed during the first 10 years (maximum excess decreases by $35 \%$ ). Then, over 40 years, there is a decrease in the maximum fixed anomalies by about $15 \%$ per 10 years. The value of the thermal field anomaly does not decrease so intensively (up to $\sim 10-13 \%$ per 10 years) $40-60$ years after the disturbances. So temperature parameters are assumed to be stabilized in this time interval. Anomalies and dynamics of spectral albedo recovery depend on the reclamation procedures in the post-technogenic area. Notably, such a high level of a relative anomaly in technogenic areas persists twice as long as in areas prone to fires, where recovery occurs naturally [17]. Long-term temporal-series analysis showed that in post-technogenic ecosystems, the properties of the upper soil horizons did not recover to the background level for a long time, and thermal regimes remained significantly anomalous for more than 60 years after technogenic impact. Thus, we suggest the formation of "neo-technogenic ecosystems" with specific thermal regimes of soils that differ from the background ones.

The dynamics of relative vegetation index anomalies of disturbed plots compared to the background $\left(\triangle \mathrm{NDVI} / \mathrm{NDVI}_{\mathrm{bg}}\right.$ ) were evaluated for the PF plots and post-technogenic plots with reclamation (BCM). Due to a lack of vegetation restoration, dynamics were not fixed for non-reclaimed plots (OMP) [12, 18, 19].

The long-term average NDVI of the background was $\sim 0.6$. After the fire (PF plots), the value of $\Delta N D V I / N D V I$ bg reached $50-65 \%$ (with sporadic maxima in some plots $\sim 80 \%$ depending on the intensity of wildfire). During $10-12$ years, the value of the vegetation index anomaly decreased to $15-18 \%$ (with sporadic maxima $\sim 26 \%$ ). After 15-20 
years (the time of stabilization $\left(\mathrm{T}_{\mathrm{stab}}\right)$ of the spectral characteristics), the amplitude of anomaly decreased to background values and could be underestimated $<5 \%$ of background values. We used exponential function to approximate $\left(\mathrm{R}^{2}=\right.$ 0.95 ) the dynamics of $\triangle \mathrm{NDVI} \mathrm{NDVI}_{\mathrm{bg}}$ (Figure $6, \mathrm{c}$ ). It should be noted [5] that the vegetation recovery rate was two times higher than the temperature anomalies recovery rate, which was also approximated by an exponential function $\left(\mathrm{R}^{2}\right.$ $=0.85$ ) (Figure 6, a, c).

In the post-technogenic BCM plot, we identified different-aged zones of a technogenic ecosystem formation since 1955. We considered the time series to analyze the dynamics of $\triangle \mathrm{NDVI} / \mathrm{NDVI}_{\mathrm{bg}}$ since the $100 \%$ anomaly after technogenic impact (Figure 6,d). Actual data show that until 2000, there was no successful restoration of vegetation. At the same time, the data obtained after 20 years show that the zones developed in a later period and reclaimed with the planting of coniferous seedlings have a more intensive vegetation restoration $[16,19]$. Thus, $\Delta \mathrm{NDVI}_{\mathrm{NDVI}} \mathrm{N}_{\mathrm{bg}}$ anomaly decreased up to $33-48 \%$ during 30 years, similar to the values for PF plots after only $\sim 5$ years of natural recovery.
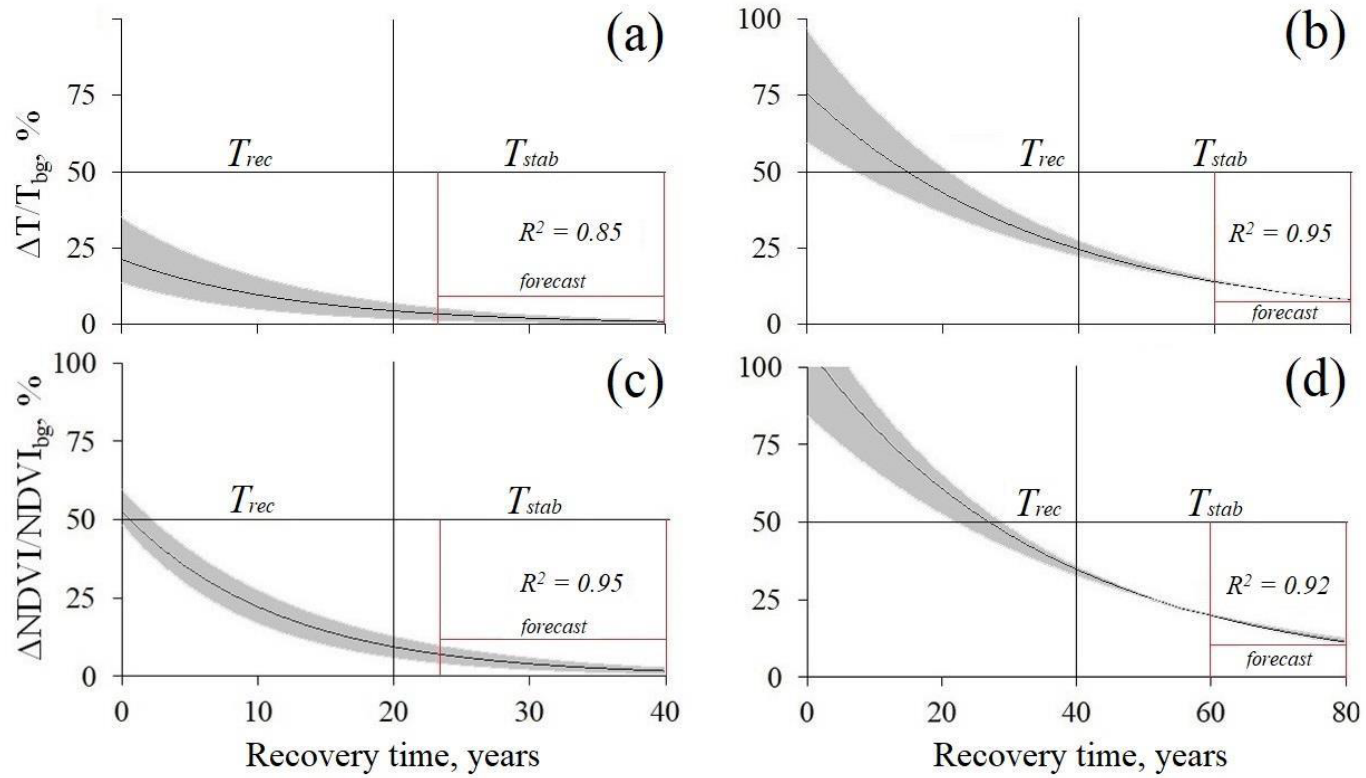

Fig. 6. Long-term dynamics of the relative anomaly in post-fire areas (a, c) and BCM plots $(b, d)$. $T_{\text {rec }}$ is a period of intensive recovery, $\mathrm{T}_{\text {stab }}$ is a period of stabilization of parameters. Standard Deviation is coloured in gray.

The peculiarity of plots after fire disturbances is that natural recovery processes occur there. The peculiarity of posttechnogenic plots is that there are two possible options for ecosystem dynamics: 1) restoration after reclamation or 2) long-term condition in the format of non-reclaimed lands (dumps, mineralized surfaces). Each of these options plays a significant role in forming surface temperature anomalies and their effect on the properties of soil horizons [4, 12, 17$19]$.

\section{Conclusions}

Under conditions of the same insolation, plots with disturbances in the upper soil horizons and ground cover are accompanied by the formation of long-term surface temperature anomalies. Similar processes were recorded for both natural (post-fire) and post-technogenic landscapes. Within 20 years, the thermal insulation properties of the vegetation cover restore in the post-fire areas. Thus, the relative temperature anomaly reaches the level of the mathematical error of measurement. In post-technogenic plots, conditions are more "contrast" compared to the background, and the restoration of the thermal regime takes longer time ( $>60$ years). "Neo-technogenic ecosystems" are formed, characterized with special thermal regimes of soils that differ from the background ones both for reclaimed (BCM) and for non-reclaimed (OMP) plots. Thus, surface thermal anomalies monitoring can be used as an additional diagnostic criterion of post-technogenic ecosystems state in the context of territories (and ecosystems) recovery after technogenic impacts.

Using time series of satellite data (Landsat and Terra/MODIS), indirect assessments of disturbed ecosystems recovery is possible in terms of disappearing the spectral features anomaly (spectral albedo in the short-wavelength bands and NDVI) compared to characteristics of the background areas.

Remote sensing data make it possible to effectively monitor the state of disturbed territories on the scale of regions and natural zones. The proposed approach, based on the use of the thermal range, extended the limit of remote monitoring of the state of disturbed ecosystems to 20-40-60 years with the ability to control and predict the dynamics of recovery processes based on periodic satellite infrared surveys of the territory. 


\section{Acknowledgments}

The present study was performed using the subject of project of IF SB RAS no. 0287-2021-0010. This research was partly funded by the Russian Foundation for Basic Research (RFBR) and Government of the Krasnoyarsk krai, and Krasnoyarsk krai Foundation for Research and Development Support, no. 20-44-242002 ("Instrumental monitoring of physical properties and numerical modeling of the state of technogenically disturbed soils in Siberia").

\section{References}

1. S.A. Bartalev, F.V. Stytsenko, V.A. Egorov, E.A. Lupyan, Lesovedenie, 2, 83-94 (2015)

2. V.G. Bondur, K.A. Gordo, V.L. Kladov, Izvestiya, Atmos. Ocean. Phys., 53, 859-874 (2017)

3. A.A. Knorre, A.V. Kirdyanov, A.S. Prokushkin, P.J. Krusic, U. Buntgen, Sci. Total Environ, 652, 314-319 (2019)

4. L. Orgogozo, A.S. Prokushkin, O.S. Pokrovsky, C. Grenier, M. Quintard, J. Viers, S. Audry, Permafrost and Periglac Process, 30, 75-89 (2019)

5. A. Kirdyanov, M. Saurer, R. Siegwolf, A. Knorre, A.S. Prokushkin, O. Churakova, M.V. Fonti, U. Büntgen, Env. Res. Let., 15, 034061 (2020)

6. E.I. Ponomarev, O.V. Masyagina, K.Y. Litvintsev, T.V. Ponomareva, E.G. Shvetsov, K.A. Finnikov, Forests, 11, 790 (2020).

7. E.I. Ponomarev, T.V. Ponomareva, Contemporary Problems of Ecology, 11, 420-427 (2018)

8. V.I. Kharuk, E.I. Ponomarev, G.A. Ivanova, M.L. Dvinskaya, S.C.P. Coogan, M.D. Flannigan, Ambio, 50, 19531974 (2021)

9. K.V. Krasnoshchekov, A.V. Dergunov, E.I. Ponomarev, Current problems in remote sensing of the Earth from space, 16, 87-97 (2019)

10. Ł. Uzarowicz, P. Charzyński, A. Greinert, P. Hulisz, C. Kabała, G. Kusza, W. Kwasowski, A. Pędziwiatr, Soil Science Annual, 4, 281-299 (2020)

11. N. Mishra, Md.O. Haque, L. Leigh, D. Aaron, D. Helder, B.L. Markham, Remote Sens, 6, 12619-12638 (2014)

12. A. Dymov, E. Abakumov, I. Bezkorovaynaya, A. Prokushkin, Y. Kuzyakov, E. Milanovsky, Theoretical Ecology, 4, 13-23 (2018)

13. A.P. Abaimov, A.I. Bondarev, O.A. Zyryanova, S.A. Shitov, Nauka, 705 (1997)

14. A.A. Dymov, Y.A. Dubrovsky, D.N. Gabov, Eurasian Soil Sc, 47, 47-56 (2014)

15. N.S. Mergelov, Izv. Ross. Akad. Nauk, Ser. Geogr, 3, 129-140 (2015)

16. T.V. Ponomareva, N.M. Kovaleva, A.S. Shishikin, E.I. Ponomarev, Gornyi Zhurnal, 10, 48-53 (2020).

17. I.N. Bezkorovaynaya, I.V. Borisova, A.V. Klimchenko, O.M. Shabalina, L.P. Zakharchenko, A.A. Ilyin, A.K. Beskrovny, Bulletin of KSAU, 9, 181-189 (2017)

18. S.G. Kornienko, Earth's Cryosphere, 21, 93-104 (2017) 